\title{
Dampak Valentine Day Terhadap Mental Health Remaja
}

\author{
Diah Yusmiranti ${ }^{1}$, Novita Sari, Siti Habibah, Henny Purnamawati, \\ Nurul Hasanah, Syarifah Ida Farida ${ }^{2 *}$ \\ Prodi Manajemen, Universitas Pamulang \\ Diahyr19@gmail.com ${ }^{1}$,Dosen01477@unpam.ac.id ${ }^{2 *}$
}

Received 26 April 2021| Revised 26 April 2021 | Accepted 27 April 2021

*Korespondensi Penulis

\begin{abstract}
Abstrak
Pertemanan pada era digital saat ini banyak dilakukan secara online dimana seseorang mengenal orang lain tanpa perlu bertemu terlebih dahulu, hal ini membuat munculnya perkumpulan pertemanan tanpa mengeketahui latar belakang seseorang ditambah muncul tindak kejahatan pada pertemanan seperti ini sering terjadi. Tujuan Pengabdian Kepada Masyarakat (PKM) Mahasiswa ini adalah untuk memberikan pengetahuan dan pemahaman kepada anggota Yayasan Mabrur RT. 04/01 Bambu Apus - Tanggerang Selatan. Adapun Metode kegiatan ini adalah mendatangi yayasan tersebut dan melakukan diskusi mengenai pentingnya mengetahui dampak dari perayaan Valentine Day Terhadap mental Health Remaja. Hasil dari kegiatan tersebut adalah para peserta menjadi lebih mengerti dan paham mengenai dampak yang terjadi pada mental health remaja sehingga kedepannya remaja dari anggota Yayasan Mabrur akan lebih memperhatikan dan menjaga lingkungan pertemanan yang memepengaruhi kesehatan mental remaja dan pada akhirnya dengan mental yang kuat membantu remaja menjadi SDM yang berkualitas.
\end{abstract}

Kata Kunci: Era digital; Mental Health; Pertemanan; Remaja.

\begin{abstract}
Friendship in digital era is currently mostly done online where someone knows other people without the need to meet first, this makes the emergence of friend groups without knowing someone's background plus crime occurs in friendships like this often happens. The purpose of this Student Community Service is to provide knowledge and understanding to members of Mabrur Foundation 04rd neighbourhood, 01th hamlet, Bambu Apus - South Tanggerang. The method of this activity is to visit the foundation and hold a discussion about the importance of knowing the impact of Valentine's Day celebration on the mental health of adolescents. The result of this activity is that the participants have a better understanding and understanding of the impact that occurs on the mental health of adolescents so that in the future teenagers from members of the Mabrur Foundation will pay more attention and maintain a friendship environment that affects the mental health of adolescents and in the end with a strong mentality to help teenagers become HR quality
\end{abstract}

Keywords: Digital Era; Mental Health; Friendship; Adolescent

\section{PENDAHULUAN}

\section{Analisis Situasi Permasalahan}

Dalam kehidupan bermasyarakat akan selalu ada kelompok-kelompok orang yang menempati suatu wilayah dan komunitas tertentu. Hal ini tentu mendinamika terjadinya interaksi antar anggota masyarakat yang terkadang dipenuhi gesekan atau konflik karena banyaknya kepentingan. Oleh karena itu penciptaan organisasi agar semua berjalan dengan tertib, teratur dan saling memahami fungsi masing-masing menjadi suatu kemestian.

Organisasi kemasyarakatan tentu harus memiliki nilai-nilai yang fundamental dalam 
mempersatukan visi kehidupan bermasyarakat dalam ruang lingkup sosial. Oleh karena itu diperlukan kesamaan pandang dari semua unsur masyarakat. Yayasan Mabrur RT. 04/01 Bambu Apus - Tanggerang Selatan yang memiliki anggota merupakan pemuda dan pemudi masyarakat setempat.

Oleh karena itu kami jadikan sebagai model pembelajaran berorganisasi di masyarakat sekitar yayasan berada yang merupakan anggota dari yayasan Mabrur. Dan harapan kami kegiatan ini dapat bermanfaat bagi masyarakat sekitar serta merupakan peran nyata kehadiran mahasiswa di masyarakat.

\section{Fokus Pengabdian Kepada Masyarakat}

Fokus masalah dalam kegiatan PKM ini adalah bagaimana terbangunnya kesadaran masyarakat dalam memilih lingkungan pertemanan yang baik. Masyarakat yang dimaksud adalah anggota Yayasan Mabrur RT. 04/01 Bambu Apus - Tanggerang Selatan.

\section{Tujuan Pengabdian Kepada Masyarakat}

1. Memberi pemahaman kepada para peserta mengenai dampak perayaan Valentine Day

2. Membantu Peserta Ikut memahami dan merasakan keresahan yang terjadi pada lingkungan setelah perayaan Valentine Day

3. Memberikan pengarahan kepada peserta untuk turut menjaga lingkungan pertemanan dan memilih teman agar bersama memperoleh energi positif

\section{Kajian Pustaka}

Menurut Iswanto (2018) menyebut valentine day sebagai kepanikan moral yang terjadi ditengah masyarakat bersamaan dengan pergaulan remaja.

Sedangkan Romario dan Aisyah (2019) menyebutkan valentine day merupakan budaya barat yang masuk ke indonesia melalui majalah, film-film, MTV, musik dan fashion.

Subjek dari pengabdian ini adalah remaja, Diananda (2018) mengatakan Remaja adalah seseorang dengan rentang usia 10-21 tahun dengan beberapa perubahan fisik yang terlihat pada perempuan seperti pembesaran buah dada sedangkan pada laki-laki tumbuhnya rambut pada bagian wajah.

Menurut Reza (2015) kesehatan mental adalah kemampuan adaptasi seseorang dengan dirinya sendiri dan alam sehingga merasakan senang, lapang dan berperilaku sosial seacara normal serta mampu menghadapi dan menerima berbagai kenyataan hidup.

\section{Manfaat Pengabdian Kepada Masyarakat}

Manfaat Pengabdian yang telah kami lakukan, yaitu:

1. Para peserta menjadi sadar akan pentingnya menjaga Lingkungan pertemanan

2. Para peserta menjadi terbekali pengetahuan dalam memilih teman

3. Para peserta mulai berhati-hati dalam menyikapi segala sesuatu

\section{METODE}

Sasaran dalam pengabdian kepada masyarakat yaitu remaja anggota dari yayasan mabrurrt. 05/01 bambu apus tanggerang selatan dan pengabdian ini dilaksanakan pada selama 3 hari yaitu pada Senin s/d Rabu / 22-24 Maret 2021, metode yang digunakan adalah pemeparan materi, diskusi terbuka dengan peserta, dan pembimbingan peserta.

Kegiatan PKM ini adalah mendatangi yayasan tersebut dan memberikan pelatihan dan diskusi pentingnya mengetahui dampak valentine day pada remaja kepada anggota yayasan dan masyarakat sekitar. Adapun kedigatan yang telah kami lakukan saat PKM, disajikan dalam tabel 1 . 
Tabel 1. Kegiatan PKM

\begin{tabular}{|c|c|c|}
\hline No & Kegiatan & Keterangan \\
\hline 1 & $\begin{array}{l}\text { Penyampaian } \\
\text { Sambutan Oleh } \\
\text { tokoh masyarakat } \\
\text { dan perwakilan } \\
\text { unpam }\end{array}$ & $\begin{array}{l}\text { Ketua RT. 04/01 } \\
\text { dan Dosen } \\
\text { Pembimbing }\end{array}$ \\
\hline 2 & $\begin{array}{l}\text { Pemaparan materi } \\
\text { "Dampak } \\
\text { Valentine Day } \\
\text { Terhadap Mental } \\
\text { Health Remaja" }\end{array}$ & $\begin{array}{l}\text { Mahasiswa \& } \\
\text { Dosen } \\
\text { pembimbing }\end{array}$ \\
\hline 3 & $\begin{array}{l}\text { Tanya Jawab } \\
\text { Peserta }\end{array}$ & $\begin{array}{l}\text { Peserta, anggota } \\
\text { yayasan \& } \\
\text { masyarakat } \\
\text { sekitar }\end{array}$ \\
\hline
\end{tabular}

\begin{tabular}{lll}
\hline No & Kegiatan & Keterangan \\
\hline 4 & Ramah Tamah & Mahasiswa dan \\
& Pemberian & Tokoh \\
& cendramata pada & Masyarakat \\
& Masyarakat & \\
& sekitar & \\
\hline
\end{tabular}

\section{HASIL DAN PEMBAHASAN Hasil}

Hasil pelaksanaan PKM ini diukur dengan wawancara singkat peserta pelatihan dengan memberikan pertanyaan-pertanyaan seperti telah tergambarkan pada tabel dibawah ini.

Tabel 1. Penilaian Responden Terhadap Pelaksanaan Pelatihan

\begin{tabular}{|c|c|c|c|c|c|c|c|c|c|c|}
\hline \multirow{2}{*}{ No } & \multirow{2}{*}{ Penilaian Kegiatan } & \multicolumn{5}{|c|}{ Jawaban Peserta } & \multirow{2}{*}{$\begin{array}{c}\text { Jmh } \\
\text { peserta }\end{array}$} & \multirow{2}{*}{ Skor } & \multirow{2}{*}{$\begin{array}{c}\text { Rata- } \\
\text { rata }\end{array}$} & \multirow{2}{*}{ Keterangan } \\
\hline & & 5 & 4 & 3 & 2 & 1 & & & & \\
\hline $\mathrm{A}$ & Materi Pelatihan & 21 & 7 & 0 & 0 & 0 & 28 & 133 & 4.75 & Sangat Baik \\
\hline $\mathrm{B}$ & Fasilitator & 4 & 24 & 0 & 0 & 0 & 28 & 116 & 4.14 & Sangat Baik \\
\hline $\mathrm{C}$ & Tempat Pelatihan & 8 & 18 & 2 & 0 & 0 & 28 & 118 & 4.21 & Sangat Baik \\
\hline \multirow[t]{2}{*}{$\mathrm{D}$} & Sajian/Konsumsi & 25 & 3 & 0 & 0 & 0 & 28 & 137 & 4.89 & Sangat Baik \\
\hline & $\begin{array}{l}\text { Kesimpulan Umum } \\
\text { Pelatihan }\end{array}$ & 24 & 4 & 0 & 0 & 0 & 28 & 136 & 4.85 & Sangat Baik \\
\hline
\end{tabular}

5. Sangat Baik, 4. Baik, 3. Cukup, 2. Cukup, 1. Kurang Sekali

Adapun dokumentasi kegiatan sebagai berikut:

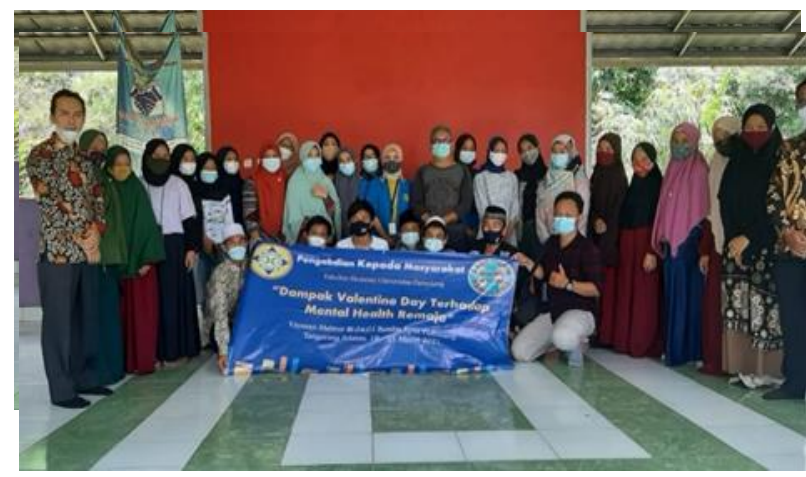

Gambar 1: Foto bersama peserta PKM

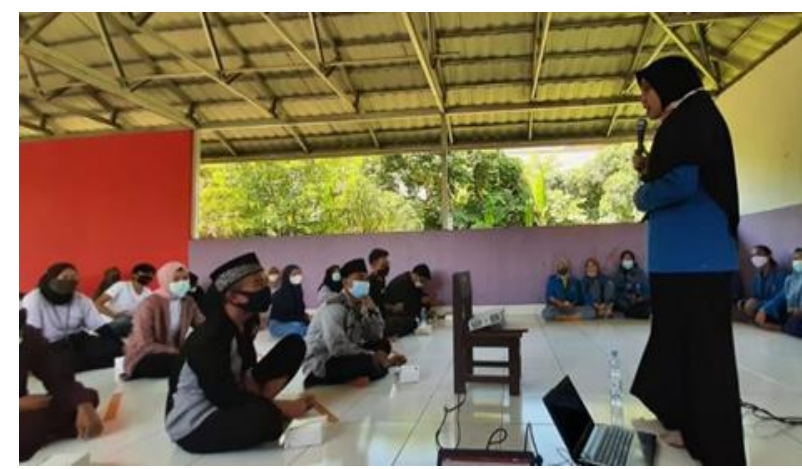

Gambar 2: Penyajian Materi dari Mahasiswa

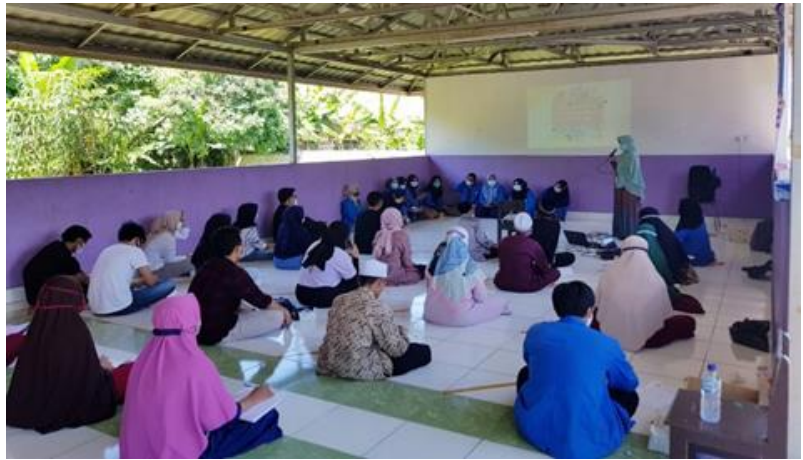

Gambar 2: Penyajian Materi dari Dosen

\section{Pembahasan}

Kesehatan mental adalah kemampuan adaptasi seseorang dengan dirinya sendiri dan alam sehingga merasakan senang, lapang dan berperilaku sosial seacara normal serta mampu menghadapi dan menerima berbagai kenyataan hidup. Pelatihan yang diikuti oleh puluhan pelajar dan remaja sekitar, dan diselenggarakan oleh dosen dan mahasiswa Program Studi Manajemen Falkultas Ekonomi Universitas Pamulang dengan Yayasan Mabrur RT. 04/01 Bambu Apus - Tanggerang Selatan. 
Kesehatan Mental merupakan komponen mendasar dari definisi kesehatan, kesehatan mental yang baik memungkinkan seseorang menyadari potensi diri mereka, mengatasi tekanan kehidupan normal, bekerja secara produktif dan berkontribusi kepada komunitas mereka, dapat disimpulkan Mental Health atau kesehatan Mental adalah adaptasi seseorang dengan diri dan lingkungannya yang memungkinkan ia untuk mengatasi permasalahan dalam kehidupan.

Tujuan Pengabdian yang telah kami lakukan, yaitu memberi pemahaman kepada para peserta mengenai dampak perayaan Valentine Day, Membantu Peserta Ikut memahami dan merasakan keresahan yang terjadi pada lingkungan setelah perayaan Valentine Day, Memberikan pengarahan kepada peserta untuk turut menjaga lingkungan pertemanan dan memilih teman agar bersama memperoleh energi positif. Masa remaja disebut juga masa pubertas, merupakan masa transisi yang unik ditandai dengan berbagai perubahan fisik, emosi dan psikis.

' Bahwa Remaja adalah seseorang individu yang baru beranjak selangkah dewasa dan baru mengenal mana yang benar dan mana yang salah, mengenal lawan jenis, memahami peran dalam dunia sosial, menerima jati diri apa yang telah dianugerahkan Allah Subhanahu wa Ta'ala pada dirinya, dan mampu mengembangkan seluruh potensi yang ada dalam diri individu",

Oleh karena itu kami jadikan sebagai model pembelajaran berorganisasi di masyarakat sekitar yayasan berada yang merupakan anggota dari yayasan Mabrur. Dan harapan kami kegiatan ini dapat bermanfaat bagi masyarakat sekitar serta merupakan peran nyata kehadiran mahasiswa di masyarakat.

Dari paparan yang telah disampaikan terkait pelaksanaan kegiatan PKM Mahasiswa Prodi Manajemen Universitas Pamulang, yang bertempat Yayasan Mabrur RT. 04/01 Bambu Apus-Tanggerang Selatan, telah mendorong suasana kebersamaan dan menjadi solusi terbangunnya mental yang baik serta pemahaman terhadap lingkungan pertemanan

\section{SIMPULAN}

Dari paparan yang telah disampaikan terkait pelaksanaan kegiatan PKM Mahasiswa Prodi Manajemen Universitas Pamulang, yang bertempat Yayasan Mabrur RT. 04/01 Bambu Apus Tangerang Selatan., telah mendorong suasana kebersamaan dan menjadi solusi terbangunnya mental yang baik serta pemahaman terhadap lingkungan pertemanan.

\section{Ucapan Terima Kasih}

Dalam kesempatan ini, perkenankanlah kami mengucapkan banyak terima kasih khususnya Ibu Sarifah Ida Farida selaku dosen Pembimbing PKM, Bapak Muhammad Ali selaku Ketua RT. 04 dan tokoh masyarakat yang telah memberikan waktu dan tempat dalam pelaksanaan PKN serta semua pihak yang telah membantu kelancaran kegiatan ini.

\section{DAFTAR PUSTAKA}

Aisyaroh, N., Kebidanan, S. P. P. D. I., \& Unissula, F. I. K. (2010). Kesehatan Reproduksi Remaja. Jurnal Majalah Ilmiah Sultan Agung. Universitas Sultan Agung.

Ayuningtyas D, Misnaniarti, Rayhani M. Analisis Situasi Kesehatan Mental Pada Masyarakat Di Indonesia Dan Strategi Penanggulangannya. Jikm [Internet]. 2018oct.10 [Cited 2021mar.29];9(1):110. Http://103.208.137.59/Index.Php/ $\mathrm{Jikm} /$ Article/View/241

Iswanto, A. (2018). Membaca Kecenderungan Pemikiran Islam Generasi Milenial Indonesia. Harmoni, 17(1), 172-179. Https://Doi.Org/10.32488/Harmoni.V17i1.299

Jannah, M. (2017). Remaja Dan Tugas-Tugas Perkembangannya Dalam Islam. Psikoislamedia: Jurnal Psikologi, 1(1).

Lubis, L. T., Sati, L., Adhinda, N. N., Yulianirta, H., \& Hidayat, B. (2019). Peningkatan Kesehatan Mental Anak Dan Remaja Melalui Ibadah Keislaman. Al- 
Hikmah: Jurnal Agama Dan Ilmu Pengetahuan, 16(2), 120-129.

Putri, A. W., Wibhawa, B., \& Gutama, A. S. (2015). Kesehatan Mental Masyarakat Indonesia (Pengetahuan, Dan Keterbukaan Masyarakat Terhadap Gangguan Kesehatan Mental). Prosiding Penelitian Dan Pengabdian Kepada Masyarakat, 2(2).

Mbaloto, F. R., Purwaningsih, D. F., \& Mutmainnah, H. S. (2020). Penyuluhan Kesehatan Tentang Seks Bebas Pada Remaja Smp Negeri 4 Sigi. Jurnal Abdidas, 1(4), 228-233.

Reza, I. (2016). Efektivitas Pelaksanaan Ibadah Dalam Upaya Mencapai Kesehatan Mental. Psikis : Jurnal Psikologi Islami, 1(1), 105-115. Http://Jurnal.Radenfatah.Ac.Id/Index.Php/Psikis/Article/View/561

Romario, R., \& Aisyah, L. (2019). Komik Islam Di Media Sosial Instagram: Dakwah Kreatif Melalui Komik. Islamuna: Jurnal Studi Islam, 6(2), 98-119. Https://Doi.Org/10.19105/Islamuna.V6i2.2588

Syam, Essy (2007). Valentine Day: Hegemoni Budaya Dan Kapitalis. Jurnal Ilmu Budaya, 3(2), Https://Doi.Org/10.31849/ Jib.V3i2.698 